\title{
Estimating Yield and Economic Loss from Constriction Canker of Peach
}

\author{
Norman Lalancette, Rutgers University, Agricultural Research and Extension Center, Bridgeton, NJ 08302; and \\ Dean F. Polk, Rutgers University, Fruit Research and Extension Center, Cream Ridge, NJ 08514
}

\begin{abstract}
Lalancette, N., and Polk, D. F. 2000. Estimating yield and economic loss from constriction canker of peach. Plant Dis. 84:941-946.

Constriction cankers, caused by Phomopsis amygdali, girdle and kill fruiting twigs which results in a direct crop loss. To quantitatively determine this loss from 1996 to 1998, the number of fruit lost per infected shoot was estimated as a function of disease incidence in 21 severely infected orchards in New Jersey. For each cultivar in 1997 and 1998, the distribution of fruit sizes at harvest and prices at shipping were used to calculate total crop value for typical expected yields. Economic loss was then calculated from yield loss and crop value estimates. The overall percent yield loss mean across all sites and cultivars, unadjusted for fruit remaining on infected shoots, was $22.2,30.7$, and $23.7 \%$ for 1996, 1997, and 1998, respectively. The frequency of these losses were not normally distributed, and the nonparametric Friedman test indicated that yield loss was significantly different among years. Assuming the remaining fruit on infected shoots were harvested, yield losses for 1997 and 1998 were 28.5 and $21.0 \%$, which translated into average economic losses of $\$ 4,009$ and 2,803/ha, respectively, for an expected yield level of 14,010 kg/ha. These loss values justify control measures for management of constriction canker in severely infected orchards.
\end{abstract}

Additional keywords: crop loss, Fusicoccum canker, peach canker, Prunus persica

Constriction canker of peach is caused by the fungus Phomopsis amygdali (Del.) Tuset \& Portilla. The name and identification of the pathogen has been in question in past studies, with both Fusicoccum and Phoma as suggested genera $(9,17,21)$. However, a relatively recent taxonomic study redesignated the causal agent from Fusicoccum amygdali to P. amygdali (18). Furthermore, a disease caused by a Phomopsis sp. was recently reported in Georgia (19), and isolates from Georgia as well as from South Carolina were subsequently identified as $P$. amygdali (7). Although $F$. amygdali was initially proposed in 1941 as the causal agent in New Jersey (11), recent isolates have been confirmed to be $P$. amygdali based on morphological characteristics (D. Farr, personal communication).

The pathogen infects peach twigs through fresh leaf scars in the fall and through buds, bud scale scars, blossoms, and fruit scars in the spring $(2,3,9)$. The resulting symptoms consist of reddishbrown elongate cankers centered about twig nodes. By the following summer, these cankers, now sunken and tan to silver in appearance, have completely girdled and killed the shoots. Foliage distal to the can-

Corresponding author: N. Lalancette

E-mail: 1alancette@aesop.rutgers.edu

Accepted for publication: 8 May 2000.

Publication no. D-2000-0615-01R

(c) 2000 The American Phytopathological Society ker desiccates quickly, but remains attached, resulting in the characteristic shoot blight phase of the disease. Infected shoots are the fruit-bearing shoots for the current growing season; therefore, shoot death results in direct fruit loss. Most fruit on infected shoots shrivel up and drop off as the shoots desiccate. Shoots having more advanced cankers are often killed prior to or during bloom and fruit set.

Constriction canker was first observed in commercial New Jersey orchards in 1934 and the first confirmed report of this disease in New Jersey, as well as on samples from Rhode Island, was in 1941 (6,11). In fall of 1949, significant canker development was observed on the eastern shore of Maryland, followed by an outbreak of shoot blight in spring and summer of 1950 (20). By the late 1950s, major epidemics occurred in southern New Jersey and additional observations of the disease had been reported in Delaware, New York, Massachusetts, and Virginia (6).

Constriction canker continues to cause significant shoot death and fruit loss in peach orchards in New Jersey and neighboring Mid-Atlantic states. Many orchards in New Jersey have at least one or more peach or nectarine blocks with moderate to severe infection. However, no quantitative data are available on the degree of yield loss in these blocks and its accompanying economic impact. Such information is vital for justification of control measures and for aiding in decisions on research priorities as well as pesticide regulations. A number of management strategies are un- der investigation and may require significant input of grower resources.

The objectives of this study were to (i) estimate yield loss from constriction canker in commercial New Jersey peach orchards, (ii) translate fruit loss from cankers into economic loss, and (iii) examine the variation in losses from canker over a three-year period. Emphasis was placed on surveying moderate to severely infected peach blocks, because these were the most likely candidates for future disease control. Such blocks also serve as inoculum sources for subsequent spread of disease to newly planted orchards. Therefore, instead of calculating statewide crop loss estimates, the focus of this study was to determine yield loss in orchards where disease management practices would be applied. Yield loss results from the first two years of this study have been recently reported (13).

\section{MATERIALS AND METHODS}

Orchard site selection. Although many commercial peach orchards in New Jersey have some level of constriction canker, no prior disease incidence data were available to allow selection of the most severely infected blocks. Consequently, sites were initially chosen based on discussions with growers, agricultural agents, and Integrated Pest Management (IPM) program associates. The search was limited to the lower one-third or coastal plain region of the state, where approximately $90 \%$ of the state's peach production occurs (1).

From the initial list, 21 commercial peach blocks having moderate to severe levels of infection were selected based on individual orchard inspections. Inclusion of sites from several different counties was a secondary criterion, so that the entire peach-growing region would be represented in the survey. No attempt was made to choose a particular cultivar or to have the same cultivar represented in each county. To simplify site identification for the study, each site was coded according to county, orchard number, and block number.

In each county, chosen orchards were located 4 to $5 \mathrm{~km}$ from each other. Within each orchard, peach blocks were never adjacent to each other, and in many cases they were as much as $1 \mathrm{~km}$ apart. The only exception to this rule was the two blocks at the $\mathrm{G} 2$ orchard, which were adjacent to each other. One abandoned orchard site, A1-2, was chosen for comparison purposes.

Sampling. During the summers of 1996, 1997, and 1998, six trees were selected for 
assessment from each orchard block. To locate these trees, three rows were chosen which divided the block lengthwise into quarters: the middle row and two rows situated halfway between the middle and end rows. For each row, two numbers between 5 and $(N-8) / 2$, where $N$ is the total number of trees within each row, were randomly selected. These numbers represented the location of the two sample trees within each row by counting trees from each end of the block. This semi-random approach allowed sampling from any size or shape of block and avoided border effects by limiting tree selection to the inner portion of the blocks.

On each selected tree, four limbs or large branches at $90^{\circ}$ intervals around the tree's circumference, starting at either side of the tree perpendicular to the row, were chosen for observation. This approach resulted in two limbs being located in the tree row and two limbs adjacent to the sod middles. If no limb was present at the designated location, then the next limb immediately to the right of the $90^{\circ}$ mark was selected.

On each of the four limbs in each year of the study, the number of healthy shoots, the number of infected shoots, and the total number of fruit observed on the healthy shoots were counted and recorded. Although most infected shoots lost all or the majority of fruit, some shoots observed in 1996 still had attached fruit at the time of assessment. These fruit were always situated below the canker. Thus, in 1997 and 1998 , the number of healthy fruit on diseased shoots was also recorded.

Only 1-year-old fruit-bearing wood, those shoots produced during the previous growing season, were assessed. Current season shoots do not produce fruit and therefore were not included in the evaluation. Constriction canker has not been reported nor was it observed on 2-year-old and older wood, so these portions of the limbs were not assessed.

Yield loss. The number of fruit lost on each limb (FL) was estimated as a function of disease incidence using the equation

$\mathrm{FL}=I \times F / S$

(equation 1)

where $\mathrm{I}=$ number of infected shoots, $\mathrm{F}=$ number of fruit on healthy shoots, and $\mathrm{S}=$ number of healthy shoots. The proportion of yield loss (YL) was then calculated as

$\mathrm{YL}=[\mathrm{FL} /(\mathrm{FL}+F)]$

(equation 2)

where FL + F represents the total number of expected fruit in the absence of disease. The four YL values calculated for each limb were then averaged to obtain an overall estimate of proportional yield loss for each tree.

Observations on the number of fruit on diseased shoots were made in 1997 and 1998; therefore, an adjusted fruit loss was also calculated for these years. Assuming that healthy fruit on diseased shoots sur- vived to be harvested, fruit loss per limb was estimated by using the equation

$\mathrm{FL}=(I \times F / S)-\mathrm{FI}$ (equation 3)

where FI = number of fruit on infected shoots. Equation 3 was then substituted into equation 2 to estimate yield loss adjusted for fruit remaining on diseased shoots.

The populations of tree yield loss means for each year of the study were tested for normality using the Wilk-Shapiro test in the SAS univariate procedure (SAS Institute, Inc., Cary, NC). An overall comparison of yield loss among years was performed using the nonparametric Friedman test (14), which was extended for using individual tree observations. Using this procedure, the trees were ranked across all years within each peach block. The sum of the rankings for each year were then used to calculate the extended Friedman statistic, $\mathrm{F}_{\mathrm{e}}$, which follows the $\chi^{2}$ distribution, with $k-1$ degrees of freedom $(k=3$ years). Only those sites having data available for all three years were used in this analysis. Thus, only the unadjusted values of the same set of cultivars and numbers of blocks of each cultivar were examined.

Economic loss. Peach price and packing data were needed to determine economic loss from constriction canker in 1997 and 1998. This information was obtained from grower surveys conducted by the Rutgers Tree Fruit IPM Program, the New Jersey Department of Agriculture, and the New Jersey Agricultural Statistical Service. IPM program surveys of grower packing results were completed during the fall and winter following each growing season. Only those orchards having the same cultivars examined for yield loss were included in the analysis.

Crop values were determined from the actual prices received for each cultivar and were also dependent on yield, the distribution of fruit sizes, and the price per kilogram per fruit size. Fruit size categories ranged from $5.1 \mathrm{~cm} \mathrm{(2} \mathrm{in)} \mathrm{through} 8.9 \mathrm{~cm}$ (3.5 in), with larger fruit usually generating higher prices. Harvest times varied from mid- to late July for the cultivars Jerseyland and Redhaven through early September for Autumnglo and Encore. Prices for each size category of each cultivar, $\mathrm{P}_{\mathrm{S}}$, were obtained at the time of shipping, because these prices fluctuate through the harvest season. Only those prices for U.S. extra \#1 grade were used in the calculations. The proportion of fruit graded into each size category, $\mathrm{F}_{\mathrm{S}}$, was calculated from packing data.

Fruit size and price data were obtained from packing facilities that served many orchards; therefore, no actual values for yield per hectare were available. Thus, crop values for each cultivar were calculated for three expected yields $\left(\mathrm{Y}_{\mathrm{E}}\right)$ that span the potential range for New Jersey orchards. These values of $8,406,14,010$, and $16,812 \mathrm{~kg} / \mathrm{ha} \quad(7,500,12,500$, and $15,000 \mathrm{lb} / \mathrm{acre})$ represented those years having low, moderate, and high yields, respectively. Actual yields are dependent on abiotic factors, such as the weather, other pest and disease losses, and many crop attributes and management practices, including tree size, tree age, training method, and planting density.

Determination of crop value for each cultivar was achieved by performing three sequential calculations. First, the per hectare yield for each fruit size, $Y_{S}$, was calculated as

$Y_{S}=F_{S} \times Y_{E}$

(equation 4)

for each expected yield $Y_{E}$. The per hectare dollar value of each fruit size, $V_{S}$, was then expressed as

$V_{S}=Y_{S} \times P_{S}$

(equation 5)

Finally, the total per hectare crop value for any given cultivar and level of expected yield, $\mathrm{V}_{\mathrm{T}}$, was then calculated by summing over all yield values for each fruit size

$V_{T}=\Sigma V_{S}$

(equation 6)

Given these estimated crop values, the economic loss, $\mathrm{E}_{\mathrm{L}}$, for each combination of cultivar and expected yield was expressed as

$E_{L}=V_{T} \times Y_{L}$

(equation 7)

Economic loss values were only calculated for adjusted yield loss estimates.

\section{RESULTS}

Yield loss. Within any given year, levels of yield loss observed in individual orchard blocks were similar in each of the four counties surveyed (Table 1). Mean unadjusted yield losses across all three years ranged from 17.1 to $43.0 \%$. The widest range of unadjusted (adjusted) yield loss, 11.4 to $58.8 \%$ (7.6 to $57.0 \%$ ), was obtained in 1997 in the A2-2 and A1-1 peach blocks, respectively. The abandoned Jerseyglo site, A1-2, had losses similar to the three other Jerseyglo sites, and was ranked fifth overall when comparing unadjusted means of all three years.

The effect of site on yield loss was evident when examining data dispersion across each of the five Redhaven blocks (Table 1). Unadjusted (adjusted) yield loss ranges at these sites in 1996, 1997, and 1998 were 12.8, 20.5 (22.6), and 10.1 (9.6)\%, respectively. The overall yield loss mean across all three years at site G1-2 was approximately twice that at A2-2.

The Wilk-Shapiro test statistics for the populations of unadjusted tree yield loss means were significant $(P \leq 0.05)$ for each year of the study. This outcome indicated that yield loss is not normally distributed, which is also evident in the frequency and cumulative distributions (Fig. 1). The 1996 and 1998 histograms show distributions skewed to the left, with a significant number of trees having 15 to $25 \%$ yield loss in 
1996 and 15 to $30 \%$ yield loss in 1998 . However, in 1997, the data distribution broadens, with many more trees having high levels of yield loss, the maximum unadjusted and adjusted levels attained being 68.2 and $67.9 \%$, respectively. This increase and decrease in yield loss across years is further indicated by unadjusted (adjusted) mean yield loss values of 22.2, 30.7 (28.5), and 23.7 (21.0)\% for 1996, 1997, and 1998, respectively.

A total of 17 peach orchard blocks were used in the nonparametric comparison of unadjusted yield loss across years. The sum of tree yield loss rankings were 828, 1,174, and 905 for 1996, 1997, and 1998 data, respectively. These values yielded a Friedman test statistic of $\mathrm{F}_{\mathrm{e}}=$ 22.7 , with $\chi^{2}{ }_{.05}(2)=5.99$. Since $22.7>$ 5.99 , significant yield loss differences existed among years. The rank sum values indicated that yield loss was considerably higher in 1997, which corroborates the observed shift in means and frequency histograms.

The adjustment of yield loss for fruit observed on infected shoots at the time of assessment resulted in a slight decrease in the estimated values for most sites (Table 1). In 1997, the difference between unad- justed and adjusted values ranged from 0.7 to $3.8 \%$, whereas this difference ranged from 0.6 to $4.8 \%$ in 1998 . Average adjustments calculated across all sites in 1997 and 1998 were 2.1 and $2.7 \%$, respectively. As would be expected, the adjustment caused a shift in the frequency and cumulative distributions toward lower yield loss values (Fig. 1). This shift is particularly evident in the 1998 histograms, where the frequency of adjusted tree means is always less than the unadjusted means for values greater than $25 \%$ yield loss, whereas the converse is true for values at and below $25 \%$ yield loss.

Economic loss. The distribution of observed fruit sizes was dependent on both cultivar and year of assessment. However, the majority of harvested fruit across most cultivars and both years tended to occur in the 6.4-, 6.7-, and 7.0-cm size categories. Fruit within this size range constituted 67.2 and $71.7 \%$ of the fruit harvested in 1997 and 1998, respectively. As expected, selling prices also varied among cultivars and between years, because this factor is dependent on time of harvest, a cultivar trait, in relation to the local and nationwide supply of fruit. Selling prices, averaged across all size categories, ranged from $\$ 0.81 / \mathrm{kg}$ for Harcrest to $\$ 1.01 / \mathrm{kg}$ for Jerseyland in 1997 and from $\$ 0.80 / \mathrm{kg}$ for Loring to $\$ 0.95 / \mathrm{kg}$ for Autumnglo in 1998 .

Estimated crop values ranged from $\$ 7,728 /$ ha for a light yielding crop on Loring in 1997 to $\$ 18,667 /$ ha for a heavy crop on Autumnglo in the same year (Table $2)$. Average crop values calculated across all varieties were $\$ 8,424,14,040$, and $16,847 /$ ha for low, moderate, and high cropping seasons, respectively, in 1997. Average values for 1998 were slightly lower at $\$ 8,249,13,749$, and $16,499 /$ ha for the same three yield levels.

Economic loss, as calculated from estimated adjusted yield loss and crop values for each cultivar, varied considerably across test sites, although the variation was less in 1998 (Table 3). Within a given yield level $Y_{E}$ in 1997, the cost of fruit loss for the most severely infected site, A1-1, was 8.5 times greater than the cost at the least infected site, A2-2. However, in 1998, the site with the greatest loss, B1-2, had a cost of fruit loss only 2.7 times that of the one with the least loss, A2-2. Average economic losses across all sites for the moderate $14,010 \mathrm{~kg} / \mathrm{ha}$ yield level in 1997 and 1998 were estimated at $\$ 4,009$ and $2,803 /$ ha, respectively.

Table 1. Estimated percent yield loss from constriction canker in severely infected commercial New Jersey peach orchard blocks

\begin{tabular}{|c|c|c|c|c|c|c|c|c|c|c|}
\hline \multirow[b]{3}{*}{ Site $^{b}$} & \multirow[b]{3}{*}{ Cultivar } & \multicolumn{9}{|c|}{ Yield loss $(\%)^{\mathrm{a}}$} \\
\hline & & \multirow{2}{*}{$\begin{array}{c}1996 \\
\text { Unadj }\end{array}$} & \multicolumn{3}{|c|}{1997} & \multicolumn{3}{|c|}{1998} & \multicolumn{2}{|c|}{ 1996-98 Unadj } \\
\hline & & & Unadj & Adj & Diff & Unadj & Adj & Diff & Mean & Rank \\
\hline \multicolumn{11}{|l|}{ Cumberland } \\
\hline C1-1 & Jerseyglo & 27.9 & 34.7 & 33.2 & 1.5 & 21.5 & 19.7 & 1.8 & 28.0 & 6 \\
\hline $\mathrm{C} 1-2$ & Encore & 31.7 & 22.7 & 19.4 & 3.3 & 24.9 & 22.2 & 2.7 & 26.4 & 8 \\
\hline $\mathrm{C} 1-3^{\mathrm{c}}$ & Biscoe & 52.9 & 53.3 & 50.8 & 2.5 & $\ldots$ & $\ldots$ & $\ldots$ & 53.1 & $\ldots$ \\
\hline $\mathrm{C} 2-1^{\mathrm{c}}$ & Harcrest & $\ldots$ & 12.9 & 12.2 & 0.7 & 17.9 & 15.7 & 2.2 & 15.4 & $\ldots$ \\
\hline $\mathrm{C} 2-2$ & Jerseyglo & 24.5 & 14.8 & 13.4 & 1.4 & 23.8 & 20.0 & 3.8 & 21.0 & 12 \\
\hline $\mathrm{C} 2-3^{\mathrm{c}}$ & Redhaven & 30.6 & $\ldots$ & $\ldots$ & $\ldots$ & $\ldots$ & $\ldots$ & $\ldots$ & $\ldots$ & $\ldots$ \\
\hline \multicolumn{11}{|l|}{ Camden } \\
\hline A1-1 & Autumnglo & 27.3 & 58.8 & 57.0 & 1.8 & 20.9 & 17.6 & 3.3 & 35.6 & 2 \\
\hline$A 1-2^{d}$ & Jerseyglo & 16.2 & 42.9 & 39.3 & 3.6 & 25.7 & 23.6 & 2.1 & 28.3 & 5 \\
\hline A $2-1$ & Cresthaven & 14.8 & 17.4 & 15.6 & 1.8 & 19.1 & 16.9 & 2.2 & 17.1 & 16 \\
\hline A2-2 & Redhaven & 17.8 & 11.4 & 7.6 & 3.8 & 15.2 & 12.8 & 2.4 & 14.8 & 17 \\
\hline A3-1 & Harbrite & 18.3 & 37.4 & 35.0 & 2.4 & 31.0 & 28.3 & 2.7 & 28.9 & 4 \\
\hline A3-2 & Sunqueen & 17.5 & 29.4 & 28.3 & 1.1 & 23.6 & 21.5 & 2.1 & 23.5 & 10 \\
\hline $\mathrm{A} 4-1^{\mathrm{c}}$ & Jerseyglo & 16.4 & $\ldots$ & $\ldots$ & $\ldots$ & $\ldots$ & $\ldots$ & $\ldots$ & $\ldots$ & $\ldots$ \\
\hline \multicolumn{11}{|l|}{ Burlington } \\
\hline B1-1 & Autumnglo & 21.2 & 43.6 & 41.4 & 2.2 & 31.4 & 26.6 & 4.8 & 32.1 & 3 \\
\hline B1-2 & Biscoe & 31.7 & 57.2 & 55.3 & 1.9 & 40.0 & 35.6 & 4.4 & 43.0 & 1 \\
\hline \multicolumn{11}{|l|}{ Gloucester } \\
\hline G1-1 & Encore & 18.1 & 23.6 & 21.6 & 2.0 & 17.6 & 16.5 & 1.1 & 19.8 & 13.5 \\
\hline G1-2 & Redhaven & 26.4 & 31.9 & 30.2 & 1.7 & 25.1 & 22.2 & 2.9 & 27.8 & 7 \\
\hline G2-1 & Jerseyland & 17.2 & 31.9 & 29.6 & 2.3 & 21.2 & 17.8 & 3.4 & 23.4 & 11 \\
\hline G2-2 & Redhaven & 24.5 & 24.1 & 21.9 & 2.2 & 25.3 & 22.4 & 2.9 & 24.6 & 9 \\
\hline G3-1 & Loring & 21.6 & 21.6 & 20.4 & 1.2 & 16.2 & 15.6 & 0.6 & 19.8 & 13.5 \\
\hline G3-2 & Redhaven & 20.8 & 18.4 & 15.7 & 2.7 & 20.0 & 17.1 & 2.9 & 19.7 & 15 \\
\hline Annual loss/diff e & $\ldots$ & 22.2 & 30.7 & 28.5 & 2.1 & 23.7 & 21.0 & 2.7 & 25.5 & $\ldots$ \\
\hline
\end{tabular}

a Unadjusted (Unadj) estimates assumed fruit observed on infected shoots at time of assessment will be lost, whereas adjusted (Adj) estimates assumed these fruit will be harvested. The difference (Diff) between the unadjusted and adjusted estimates was calculated as Diff = Unadj - Adj. Unadjusted yield loss means calculated across all three years were ranked (Rank) from highest to lowest loss in ascending order, with the highest mean yield loss beginning at Rank $=1$.

${ }^{\mathrm{b}}$ Site code format was $\mathrm{XY}-\mathrm{Z}$, where $\mathrm{X}=$ letter indicating county $(\mathrm{C}=$ Cumberland, $\mathrm{A}=$ Camden, $\mathrm{B}=$ Burlington, and $\mathrm{G}=\mathrm{Gloucester}), \mathrm{Y}=$ commercial orchard number within county, and $\mathrm{Z}=$ block number within that grower's orchard.

${ }^{c}$ Missing data for sites C1-3, C2-3, and A4-1 were due to tree removal; site C2-1 was added in this orchard as replacement for site C2-3.

${ }^{\mathrm{d}}$ Site A1-2 was an abandoned orchard included for comparison.

e To allow meaningful comparisons across years, average annual yield losses and differences (Diff = Unadj - Adj) were calculated only from those orchard blocks that provided data for all three years (17 blocks total). Thus, blocks C1-3, C2-1, C2-3, and A4-1 were excluded from this summary. 


\section{DISCUSSION}

Although quantitative yield loss estimates have not been previously reported for constriction canker of peach, some field observations are available for comparison. The outbreak that occurred in Maryland during 1949 and 1950 was so severe that trees of the susceptible cultivar Golden Jubilee were removed from orchards (20).
Thousands of peach trees were uprooted in New Jersey during the 1940s and 1950s following severe epidemics during which crop losses of more than $50 \%$ were common on susceptible cultivars (4). This level of yield reduction agrees with the highest estimates obtained during 1997 in this study, during which 51 to $57 \%$ of the fruit were lost on Biscoe and Autumnglo.
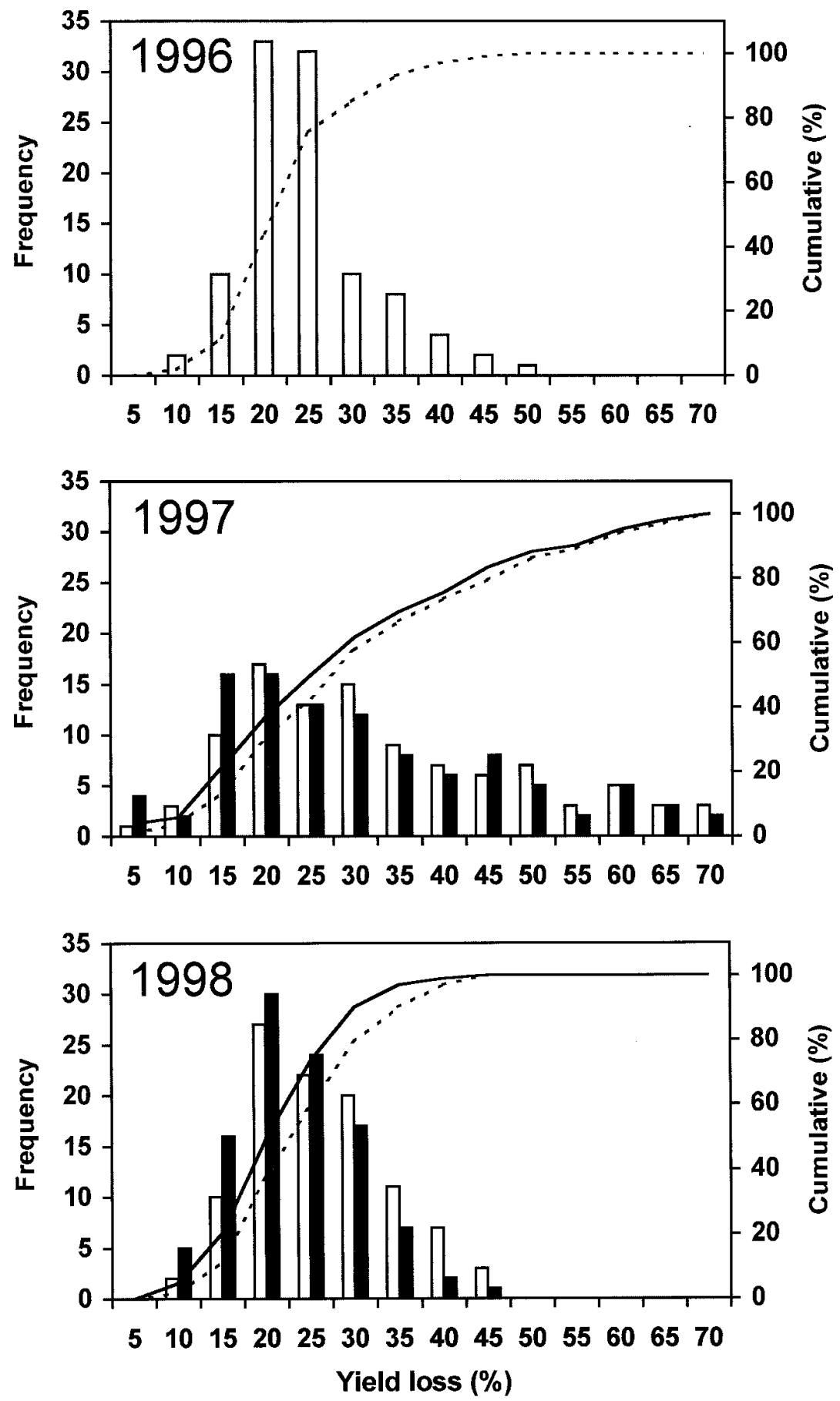

Fig. 1. Frequency (bar) and cumulative (line) yield loss distributions for peach trees having moderate to severe constriction canker in 17 commercial New Jersey orchards. Yield loss estimates were derived from six trees that were assessed in the same orchard blocks in each year of the study, for a total of 102 observations per year. Frequency counts for each histogram bar include all those values greater than the previous bar value up to and including the current bar value (e.g., 30\% yield loss bar range is $25<$ value $\leq 30$ ). Adjusted estimates (solid bars and lines) assume fruit below cankers on bearing shoots will be harvested, while unadjusted estimates (open bars, dashed lines) assume these fruit will be lost to disease.

Similarly, a grower removed one of these blocks as a result of the overwhelming incidence of shoot death and fruit drop from canker.

Yield losses from other diseases and insects in New Jersey peach orchards, reported by the Rutgers Tree Fruit IPM Program for 1996 and 1997, are available for comparison (16). Average losses for insects ranged from $0.01 \%$ for plum curculio to $1.46 \%$ for catfacing insects, both in 1997 . Average losses for diseases ranged from $0.2 \%$ for rusty spot in 1996 to $7 \%$ for bacterial spot in 1997. As would be expected, these average losses were relatively low compared to those obtained for constriction canker due to the inclusion of many healthy blocks in the IPM survey. However, the maximum reported losses from the IPM survey provide a more valid comparison to the constriction canker loss estimates obtained from severely infected orchards. In 1996 and 1997, maximum losses were 18 and $14 \%$ for catfacing insects, 36 and $45 \%$ for peach scab, 30 and $78 \%$ for bacterial spot, 12 and $11 \%$ for brown rot, and 7 and $68 \%$ for rusty spot, respectively. In 1996, the highest observed constriction canker loss (unadjusted) for a surveyed block, $52.9 \%$, was greater than all other reported diseases and insects from the IPM survey. However, in 1997 the maximum canker yield loss (adjusted) of $57 \%$ was superseded by losses from both bacterial spot and rusty spot. Nevertheless, these data show that constriction canker can cause yield loss that ranks high among losses caused by other diseases.

Shoots can be killed by constriction canker prior to fruit set and fruit abscise as the shoots are girdled; therefore, there is no direct method for assessing yield loss. Thus, in this study, yield loss was indirectly estimated as a function of the incidence of cankered shoots and the number of fruit per healthy shoot. This estimation approach assumed that the number of fruit lost on infected shoots would have been equal, on average, to the number of fruit observed on healthy shoots. This assumption was valid because fruit bud initiation on new growth would have occurred during the previous summer (8), prior to any infection during the subsequent fall and following spring.

A relative comparison of cultivars for susceptibility to constriction canker was not an objective of this survey. Furthermore, cultivar types were confounded with geographical sites; therefore, a statistically valid comparison could not be performed. The importance of the site effect was evident when examining variability among the five Redhaven blocks, each located at a different site. When comparing the mean yield loss across all three years, one Redhaven block (G1-2) was observed to have approximately twice as much loss as another Redhaven block (A2-2). Differences in tree age, location to adjacent blocks with 
canker, horticultural practices such as fertilization or pruning, spray programs, and weather are some of the factors that could influence disease incidence and yield loss. Thus, a meaningful cultivar comparison would have required each cultivar to be present at each site, of similar age, and treated in an identical manner. The design and implementation of such an experiment would have been difficult or impossible using commercial orchards.

The approach used to calculate the unadjusted yield losses was independent of any indirect effects that constriction canker may have on tree vigor. A high disease incidence level and the resulting shoot death might mimic results observed after heavy pruning, which usually results in excessive vegetative growth and reduced yields (15). Severely infected trees were often observed in this study to have increased numbers of vegetative, nonbearing water sprouts. However, the unadjusted estimates were calculated as proportions and not absolute values; therefore, the equations used can be solved to show that yield loss was equivalent to disease incidence. Essentially, a given proportion of shoot death translated directly into an equal proportion of yield loss. Therefore, these unadjusted estimates were independent of the trees' actual fruit load. In contrast to unadjusted loss, adjusted yield loss values were related to but not directly

Table 2. Estimated crop values in U.S. dollars per hectare for expected yields $\left(\mathrm{Y}_{\mathrm{E}}\right)$ of those peach cultivars examined for yield loss from constriction canker

\begin{tabular}{|c|c|c|c|c|c|c|}
\hline \multirow[b]{3}{*}{ Cultivar $^{b}$} & \multicolumn{6}{|c|}{ Estimated crop values $(\$ / \mathrm{ha})^{\mathrm{a}}$} \\
\hline & \multicolumn{3}{|c|}{1997} & \multicolumn{3}{|c|}{1998} \\
\hline & $\mathbf{Y}_{\mathrm{E} 1}$ & $\mathbf{Y}_{\mathrm{E} 2}$ & $\mathbf{Y}_{\mathbf{E 3}}$ & $\mathbf{Y}_{\mathrm{E} 1}$ & $\mathbf{Y}_{\mathrm{E} 2}$ & $\mathbf{Y}_{\mathrm{E3}}$ \\
\hline Autumnglo & 9,334 & 15,556 & 18,667 & 9,009 & 15,016 & 18,019 \\
\hline Biscoe & 7,835 & 13,059 & 15,670 & 7,755 & 12,925 & 15,510 \\
\hline Cresthaven & 8,556 & 14,260 & 17,111 & 8,084 & 13,473 & 16,167 \\
\hline Encore & 8,451 & 14,086 & 16,903 & 8,844 & 14,741 & 17,689 \\
\hline Harcrest & 8,628 & 14,380 & 17,256 & 7,778 & 12,964 & 15,557 \\
\hline Jerseyglo & 8,377 & 13,961 & 16,754 & 8,550 & 14,251 & 17,101 \\
\hline Jerseyland & 8,690 & 14,484 & 17,380 & 8,472 & 14,120 & 16,944 \\
\hline Loring & 7,728 & 12,881 & 15,457 & 7,643 & 12,739 & 15,287 \\
\hline Redhaven & 8,213 & 13,689 & 16,427 & 8,108 & 13,513 & 16,215 \\
\hline
\end{tabular}

${ }^{a}$ Expected yields used in the calculations to simulate low, moderate, and high cropping seasons, were respectively, $\mathrm{Y}_{\mathrm{E} 1}=8,406, \mathrm{Y}_{\mathrm{E} 2}=14,010$, and $\mathrm{Y}_{\mathrm{E} 3}=16,812 \mathrm{~kg} / \mathrm{ha}(7,500,12,500$, and 15,000 lb/acre).

${ }^{\mathrm{b}}$ Data were not available for cvs. Harbrite and Sunqueen. equivalent to the observed levels of disease incidence. Nevertheless, the degree of correction applied was relatively small, making the assumption of independence also valid for the adjusted values.

In addition to constriction canker, the influence of other diseases and pests on the yield loss estimates needs to be considered. If fruit affected by other pests abscised prior to this survey's assessment, then the expected number of fruit per cankered shoot would have been underestimated. Conversely, if fruit affected by other pests abscised after this survey's assessment or were harvested but rejected on the packing line, then the expected number of fruit per cankered shoot would have been overestimated. In either situation, the occurrence of these additional losses would have influenced the absolute value of fruit loss from canker. However, in this study, the use of proportional loss attributed to canker, in conjunction with expected yields rather than observed yields, allowed calculation of economic losses that were in dependent of other disease and pest effects. One important and logical assumption of this independence was that these additional losses would have been equivalent on healthy and cankered shoots had the latter not become infected by $P$. amygdali.

Adjustment of the yield loss values for fruit still attached to diseased shoots provided, on average, a relatively minor correction of approximately 2 to $3 \%$. This small difference may be due to the occurrence of multiple shoot infections, which

Table 3. Estimated economic loss in U.S. dollars per hectare from constriction canker for expected yields $\left(\mathrm{Y}_{\mathrm{E}}\right)$ in severely infected commercial New Jersey peach orchards

\begin{tabular}{|c|c|c|c|c|c|c|c|}
\hline \multirow[b]{3}{*}{ Site $^{\mathbf{b}}$} & \multirow[b]{3}{*}{ Cultivar } & \multicolumn{6}{|c|}{ Economic loss $(\$ / h a)^{a}$} \\
\hline & & \multicolumn{3}{|c|}{1997} & \multicolumn{3}{|c|}{1998} \\
\hline & & $\mathbf{Y}_{\mathbf{E 1}}$ & $\mathbf{Y}_{\mathrm{E} 2}$ & $\mathbf{Y}_{\mathbf{E 3}}$ & $\mathbf{Y}_{\mathrm{E} 1}$ & $\mathbf{Y}_{\mathbf{E} 2}$ & $\mathbf{Y}_{\mathbf{E 3}}$ \\
\hline \multicolumn{8}{|c|}{ Cumberland } \\
\hline $\mathrm{C} 1-1$ & Jerseyglo & 2,781 & 4,635 & 5,562 & 1,684 & 2,807 & 3,369 \\
\hline C1-2 & Encore & 1,640 & 2,733 & 3,279 & 1,963 & 3,272 & 3,927 \\
\hline $\mathrm{C} 1-3$ & Biscoe & 3,980 & 6,634 & 7,961 & $\ldots^{c}$ & $\ldots^{c}$ & $\ldots{ }^{\mathrm{c}}$ \\
\hline C2-1 & Harcrest & 1,053 & 1,754 & 2,105 & 1,221 & 2,035 & 2,442 \\
\hline $\mathrm{C} 2-2$ & Jerseyglo & 1,122 & 1,871 & 2,245 & 1,710 & 2,850 & 3,420 \\
\hline \multicolumn{8}{|c|}{ Camden } \\
\hline A1-1 & Autumnglo & 5,320 & 8,867 & 10,640 & 1,586 & 2,643 & 3,171 \\
\hline $\mathrm{A} 1-2^{\mathrm{d}}$ & Jerseyglo & 3,292 & 5,487 & 6,584 & 2,018 & 3,363 & 4,036 \\
\hline A2-1 & Cresthaven & 1,335 & 2,224 & 2,669 & 1,366 & 2,277 & 2,732 \\
\hline A $2-2$ & Redhaven & 624 & 1,040 & 1,248 & 1,038 & 1,730 & 2,076 \\
\hline \multicolumn{8}{|c|}{ Burlington } \\
\hline B1-1 & Autumnglo & 3,864 & 6,440 & 7,728 & 2,397 & 3,994 & 4,793 \\
\hline B1-2 & Biscoe & 4,333 & 7,221 & 8,666 & 2,761 & 4,601 & 5,522 \\
\hline \multicolumn{8}{|c|}{ Gloucester } \\
\hline G1-1 & Encore & 1,826 & 3,043 & 3,651 & 1,459 & 2,432 & 2,919 \\
\hline G1-2 & Redhaven & 2,480 & 4,134 & 4,961 & 1,800 & 3,000 & 3,600 \\
\hline G2-1 & Jerseyland & 2,572 & 4,287 & 5,145 & 1,508 & 2,513 & 3,016 \\
\hline G2-2 & Redhaven & 1,799 & 2,998 & 3,597 & 1,816 & 3,027 & 3,632 \\
\hline G3-1 & Loring & 1,577 & 2,628 & 3,153 & 1,192 & 1,987 & 2,385 \\
\hline G3-2 & Redhaven & 1,289 & 2,149 & 2,579 & 1,386 & 2,311 & 2,773 \\
\hline
\end{tabular}

a Expected yields used to simulate low, moderate, and high cropping seasons were, respectively, $\mathrm{Y}_{\mathrm{E} 1}=8,406, \mathrm{Y}_{\mathrm{E} 2}=14,010$, and $\mathrm{Y}_{\mathrm{E} 3}=16,812 \mathrm{~kg} / \mathrm{ha}$ $(7,500,12,500$, and $15,000 \mathrm{lb} / \mathrm{acre})$.

${ }^{\mathrm{b}}$ Site code format was $\mathrm{XY}-\mathrm{Z}$, where $\mathrm{X}=$ letter indicating county $(\mathrm{C}=$ Cumberland; $\mathrm{A}=$ Camden; $\mathrm{B}=$ Burlington; $\mathrm{G}=\mathrm{Gloucester}), \mathrm{Y}=$ commercial orchard number within county, and $\mathrm{Z}=$ block number within that grower's orchard.

c Orchard removed after 1997.

${ }^{\mathrm{d}}$ Site A1-2 was an abandoned orchard included for comparison. 
were observed during the assessments. Additional shoot infections reduce the probability that fruit would survive on a shoot below a canker. Such multiple infections would be more likely to occur in severely infected orchards, such as those examined in this study and observed during the earlier New Jersey epidemics. For example, a nonsprayed treatment in a Jerseyland orchard during 1953 was assessed as having an average of 1.74 cankers/shoot (6). Although the number of cankers per infected shoot was not recorded in this study, the frequency of multiple infections and the location and distribution of cankers at the nodes and base of shoots are currently being examined in another experiment.

Both adjusted and unadjusted yield losses were reported to provide the minimum to maximum range of estimated loss. Due to the different cultivar harvest times, occurrence of multiple pickings per harvest, and widespread locations of the survey sites, no actual field assessments were performed to verify if the fruit below the cankers survived to be picked. However, observations in other test blocks have indicated that the majority of these fruit remain attached through harvest. Thus, we believe that the adjusted values represent the most likely and best estimate of yield loss from constriction canker. This conclusion is particularly important for low levels of infection, where the probability of multiple infections is reduced and the proportion of surviving fruit on diseased shoots would be greater.

Management of constriction canker on susceptible cultivars would require regular fungicide applications from delayed dormant stage through bloom in the spring, and throughout the leaf abscission period in the fall (21). The fall protection period may require as many as seven fungicide applications to provide continuous coverage of newly exposed leaf scars. However, except for a single copper fungicide application in late fall, no materials are currently registered for consecutive postharvest applications during the entire leaf abscission period. Furthermore, two of the most effective materials used in the past, monocalcium arsenite and glyodin $(5,6,10)$, are no longer available. Consequently, growers today do not apply the critical fall fungicide applications. These circumstances explain why the level of yield loss in the abandoned peach orchard was equivalent to that observed in commercial blocks. Furthermore, the current commercial fungicide program for controlling other diseases during this period, a dormant leaf curl spray followed by two to three bloom sprays for blossom blight control, appears to be insufficient or ineffective at providing some canker control.

A major objective of this study was to estimate the degree of economic loss for commercial orchards in New Jersey. Cost of fruit loss from constriction canker directly determines the amount of money that can be spent on control measures, namely fungicide applications or removal of cankers. As an example, the lowest economic loss encountered in the study was $\$ 624 /$ ha for a Redhaven block in Camden County. Given a moderately expensive fungicide priced at $\$ 62 /$ ha and a fungicide efficacy of $80 \%$ control, this block could be sprayed about eight times annually at a cost equaling the yield gain. For the remaining blocks in this study, which experienced higher economic losses, growers would not only recoup the cost of the fungicide but also benefit from a net economic gain.

A model was previously proposed for evaluating economic losses caused by pathogens on tree fruit (12). This model, like the approach taken in our study, utilized variables for unit pricing of fruit and yield loss relative to maximum expected yields. A component representing cost of production, particularly disease prevention measures, allowed the model to estimate changes in gross revenue. Similarly, we addressed this issue in terms of economic loss as justification for additional sprays for control. However, unlike our study, the model incorporated a variable for time to accommodate the "intertemporal dependence" that occurs in perennial crops. That is, disease occurrence and cost adjustments in any given year can have an extended effect on yield loss and revenue in subsequent years. For constriction canker, one such effect is the influence of shoot loss on horticultural management practices. Severely infected trees become devoid of vegetative and fruit-bearing wood in the lower half of the tree, while shoot growth is enhanced in the upper half. Consequently, infected trees are taller than average, requiring additional time for harvest. Furthermore, training the tree to the desired lower, vase-shaped structure becomes more labor intensive, because healthy shoots are difficult to find in the lower canopy.

Given the results of this survey, New Jersey growers can afford to manage peach constriction canker in moderate to severely infected orchards. Furthermore, after several years of good disease control, the number of fungicide applications per year or intensity of canker removal could perhaps be reduced to a "maintenance level". Past studies, which used the fungicide glyodin, indicated that a heavily diseased orchard can be rehabilitated in about three years (10). If this outcome holds true for current fungicides, there would be a delay in recouping the cost of disease control, but the near-term benefits would justify these costs. Studies are currently underway to determine the efficacy and optimum timing of currently available fungicides, as well as epidemiological strategies for reducing the number of applications.

\section{ACKNOWLEDGMENTS}

We thank B. I. Hillman and S. A. Johnston for reviewing this manuscript prior to submission for publication, and D. M. Robison for technical assistance in data manipulation.

\section{LITERATURE CITED}

1. Anonymous. 1998. New Jersey agriculture annual report and agricultural statistics. N. J. Dep. Agric. Circ. No. 550.

2. Cohoon, D. F., and Daines, R. H. 1954. Some facts about peach canker. (Abstr.) Phytopathology 44:109.

3. Cohoon, D. F., and Daines, R. H. 1956. Peach canker (Fusicoccum amygdali): times and sites of infections. Plant Dis. Rep. 40:304-308.

4. Daines, R. H. 1974. Peach canker (Fusicoccum amygdali Delacroix) present in orchards in Hammonton area. Hortic. News N. J. State Hortic. Soc. 55(4):12-13.

5. Daines, R. H., and Coohoon, D. F. 1954 Control of peach canker. (Abstr.) Phytopathology 44:109.

6. Daines, R. H., Cohoon, D. F., Leone, I., and Brennan, E. 1958. Control of Fusicoccum canker of peach by nutrition, defoliation, and protective fungicides. Phytopathology 48:400-407.

7. Farr, D. F., Castlebury, L. A., and PardoSchultheiss, R. A. 1999. Phomopsis amygdali causes peach shoot blight of cultivated peach trees in the southeastern United States. Mycologia 91(6):1008-1015

8. Flore, J. A. 1994. Stone fruit. Pages 233-270 in: Handbook of Environmental Physiology of Fruit Crops, Vol. I: Temperate Crops. B. Schaffer and P. C. Andersen, eds. CRC Press, Inc., Boca Raton, FL.

9. Guba, E. F. 1955. Some historical aspects of peach canker caused by the fungus Fusicoccum amygdali Delacr. Plant Dis. Rep. 39:771-772.

10. Guba, E. F. 1958. Pertinent aspects of the infection cycle and control of the peach canker pathogen, Fusicoccum amygdali. Plant Dis. Rep. 42:481-492.

11. Haenseler, C. M., and Daines, R. H. 1941. Peach canker caused by Fusicoccum amygdali. (Abstr.) Phytopathology 31:10.

12. Heaton, C. R., Ogawa, J. M., and Nyland, G. 1981. Evaluating economic losses caused by pathogens of fruit and nut crops. Plant Dis. 65:886-888.

13. Lalancette, N. 1998. Estimating yield loss from Fusicoccum canker in commercial New Jersey peach orchards. (Abstr.) Phytopathology 88(9):S135.

14. Neter, J., and Wasserman, W. 1974. Applied Linear Statistical Models. Richard D. Irwin, Inc., Homewood, IL.

15. Overcash, J. P. 1988. Training, pruning peach trees, southeastern U.S. Pages 508-513 in: The Peach. N. F. Childers and W. B. Sherman, eds. Horticultural Publications, Gainsville, FL.

16. Polk, D., Schmitt, D., Rizio, E., and Petersen, K. 1997. The economic impact of peach pests in New Jersey, 1996-1997. Hortic. News N. J. State Hortic. Soc. 78(1):3-10.

17. Roberts, J. W. 1940. The constriction disease of peach. Phytopathology 30:963-968.

18. Tuset, J. J., and Portilla, M. T. 1989. Taxonomic status of Fusicoccum amygdali and Phomopsis amygdalina. Can. J. Bot. 67:12751280.

19. Uddin, W., Stevenson, K. L., and PardoSchultheiss, R. A. 1997. Pathogenicity of a species of Phomopsis causing a shoot blight on peach in Georgia and evaluation of possible infection courts. Plant Dis. 81:983-989.

20. Weaver, L. O. 1951. The constriction disease of peach in Maryland. Plant Dis. Rep. 35:144.

21. Zehr, E. I. 1995. Constriction canker. Pages 31-32 in: Compendium of Stone Fruit Diseases. J. M. Ogawa, E. I. Zehr, G. W. Bird, D. F. Ritchie, K. Uriu, and J. K. Uyemoto, eds. APS, St. Paul, MN. 